\title{
Modeling Nonlinear Viscoelastic Nanoindentation of PVAc at Different Unloading Rates
}

\author{
Yilmaz Kucuk \\ Bartin University, Department of Mechanical Engineering, Turkey
}

\begin{abstract}
In this study, nanoindentation technique was used to determine the nonlinear viscoelastic behavior of polyvinyl acetate (PVAc) with a glass transition temperature of $29^{\circ} \mathrm{C}$. Nanoindentation was conducted with a Berkovich nanoindenter tip under the same constant loading rate but different unloading rates. The Burgers nonlinear viscoelastic model was implemented in ABAQUS/Standard finite element code by means of a user-defined subroutine. After fitting the complete load-displacement curves, parameters in the nonlinear Maxwell and Voigt elements were obtained to describe the nonlinear viscoelastic behavior of PVAc. The results show that PVAc exhibits negative unloading stiffness under low unloading rates. However, if the unloading rate is higher than $0.1 \mathrm{mN} / \mathrm{s}$, PVAc appears more elastic behavior. The nonlinear Burgers model used can successfully model the nonlinear viscoelastic behavior of PVAc at different unloading rates, including the unloading "nose" associated with negative unloading slope at slow unloading rate for a highly viscoelastic material.
\end{abstract}

Keywords: nanolinear viscoelastic nanoindentation, PVAc, viscoelasticity, finite element simulation, FEM, nonlinear Burgers model

\section{INTRODUCTION}

Polyvinyl acetate (PVAc) has a wide application area as general sensitive adhesives in addition to be used as a constituent in paint, textile, and paper coating products. Depending on the concentration of PVAc, the ethylene polymers find application in a range of areas including high clarity and flexible packaging materials, impact resistant footwear, and adhesives.

Nanoindentation is an effective technique to measure mechanical properties of materials and it can also characterize material behavior at micron/ submicron scale. The fundamentals of nanoindentation have been well-established [1] to measure some properties of elastic-plastic materials. However, PVAc often shows negative unloading slope, giving negative contact stiffness under nanoindentation and as a result, the elastic analysis is not appropriate to extract its viscoelastic properties. In some previous studies, the viscoelastic properties of PVAc have been examined under both linear [2] and [3] and nonlinear [4] states by the use of its time-dependent relaxation modulus and creep compliance. Huang and $\mathrm{Lu}$ [5], carried out some indentation tests on two polymeric materials (PMMA and PVAc) by using both spherical and Berkovich (three-faced) indenters. Using two different indenter shapes, they were able to evaluate two independent material relaxation functions. They employed the method of Lee and Radok [6] to incorporate viscoelastic behavior by implementing hereditary integral operators into the elastic solution expressions that were presented by Sneddon [7]. In nanoindentation, the load and deformation relations ( $P$ - $h$ curves) have been studied originally by Hertz [8] and developed by Sneddon et al., with additional studies [7], [9] and [10]. More recently Kucuk, et al. investigated the nonlinear viscoelastic nanoindentation of polymethyl methacrylate (PMMA) by modeling the complete loading and unloading curves [11].

In the past several decades, a number of authors have studied constitutive law, which emphasizes the effect of strain-induced increase in the stress relaxation process, to determine the nonlinear viscoelastic response of the polymers.

Shay and Caruthers [12] demonstrated that yield could be calculated using their constitutive equation in numerical simulations of constant extension rate experiments. Knauss and Emri [13] and [14] developed a free volume based constitutive equation. Wineman and Waldron [15] considered the effect of strain on the acceleration of stress relaxation by applying a form of their constitutive equation. By means of the linear viscoelastic operators that are employed in time-dependent integrals, material properties can be determined based on linear mechanics. However, even in the case of elastic materials, it is known that a plastic deformation zone occurs in the specimen underneath the contact area between the nanoindenter tip and test specimen. In most analytical studies on nanoindentation, only the loading portion of the response has been examined to predict the viscoelastic behavior of test materials. Recently, Wang et al. [16], performed some nanoindentation tests on PVAc to examine the viscoelastic behavior especially in nonlinear viscoelastic region. However, there is a lack of consideration to evaluate the effect of unloading portion of the response on nonlinear viscoelastic behavior of PVAc.

In this study, the nanoindentation tests including a constant loading rate and different unloading rates 
were performed to predict the nonlinear viscoelastic behavior of PVAc. The Burgers nonlinear viscoelastic model was implemented to ABAQUS/Standard code with a user-defined subroutine. After fitting the loaddisplacement curves to the simulation curves obtained from the Burgers model curves, the nonlinear behavior of PVAc could be predicted under different strain rates.

\section{THEORY}

Recently, Chen et al. [17] prepared a review paper summarizing different three-dimensional viscoelastic models, including Hooke, Newton, Maxwell, Voigt, Boltzmann, Zener, Tsay, Burgers, Weichert, and Kelvin models. The creep and stress relaxation terms cannot be described by the Maxwell and the Voigt elements, respectively [18]. The nonlinear viscoelastic behavior under all situations cannot be described by using available nonlinear viscoelastic models in the literature [19]. In this study, a phenomenological model that is generally called four-parameter Burgers model [20] was selected. The theory applied to the Burgers model has been introduced in detail in a paper recently published by Kucuk et al. [11].

\section{EXPERIMENTAL}

PVAc specimen having flat prismatic shape with thickness of $1 \mathrm{~mm}$ was cut and fixed properly on the sample tray of indentation device. Then, the nanoindentation test parameters that are necessary to input in first stage of process were recorded on the software provided by the nanoindentation device (Agilent Nano Indenter G200 system).

The nanoindentation tests were carried out with Berkovich indenter tip at the room temperature (23 $\left.{ }^{\circ} \mathrm{C}\right)$. For the load of $8 \mathrm{mN}$ with a constant loading rate of $0.05 \mathrm{mN} / \mathrm{s}$ and five unloading rates $(0.05,0.1,0.2$, 0.4 and $0.8 \mathrm{mN} / \mathrm{s}$ ) were implemented, respectively. To ensure the consistency of results obtained from loading-unloading steps, twelve nanoindentation tests in a $4 \times 3$ grid have been performed. The distance between the neighboring indents (in both $\mathrm{X}$ and $\mathrm{Y}$ directions) was selected as $100 \mu \mathrm{m}$ for each indent. All nanoindentation experiments could be started after reaching the drift rate to $0.05 \mathrm{~nm} / \mathrm{s}$ or below this rate. For simulations, the indenter was modeled as a rigid shell and full integration 3D stress elements were selected for the sample. Fig. 1 shows the mesh of $1 / 6$ symmetric PVAc sample and the nanoindenter tip.

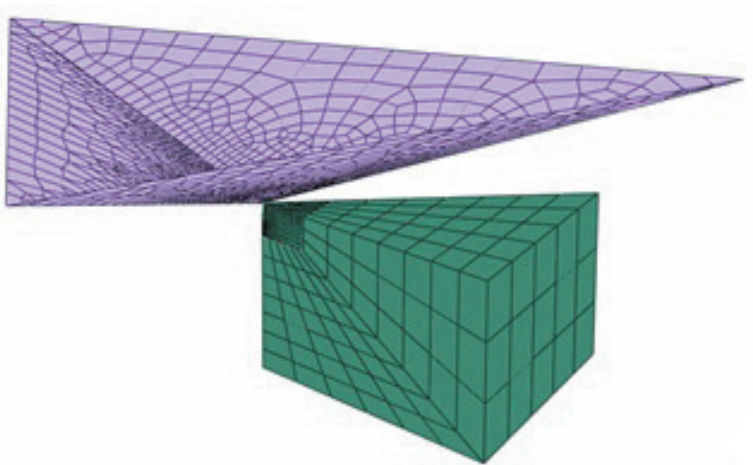

Fig. 1. Berkovich indenter using rigid shell element and 1/6 symmetric PVAc sample

\section{RESULTS AND DISCUSSION}

In this study, the nonlinear viscoelastic behavior of PVAc at different unloading rates was investigated by nanoindentation technique. The viscoelastic materials can exhibit negative stiffness during unloading part of indentation process for slow unloading rates. The Oliver-Pharr method cannot give the modulus under such a condition due to negative unloading stiffness or high unloading stiffness induced by viscoelastic effects. Burgers model parameters that are summarized in Table 1 were determined by curve fitting method between the loading-unloading and Burgers model response curves. Therefore, these material parameters are then used in the nonlinear Burgers model to simulate the nanoindentation under other unloading rates. The constant loading rate of $0.05 \mathrm{mN} / \mathrm{s}$ was used for all unloading rates. It can clearly be seen from the simulation results that the model used can capture the negative stiffness during initial unloading (Fig. 2). According to the load-displacement curves obtained from experiments and simulations, the PVAc specimen used exhibits negative stiffness in both unloading rates of 0.05 and $0.1 \mathrm{mN} / \mathrm{s}$ (Figs $2 \mathrm{a}$ and b). This behavior can be explained as creep under a low unloading rate.

At the beginning of the unloading portion, the load is almost at maximum and thus, the effect of creep is currently predominant because of the decrease slightly at maximum load. However, this viscoelastic behavior cannot be maintained for higher unloading rate due to the diminishing effect of viscosity (Figs. 2c to e). Another point that must be emphasized here is of the recovery capability of PVAc. After reaching to unloading rate of $0.1 \mathrm{mN} / \mathrm{s}$, PVAc specimen exhibited the positive stiffness and an increase in its capability of recovery was also observed. Consequently, this results support this comment that the unloading 
a1)

U, U3

- $1.531 \mathrm{E}+03$

$\square 1.404 \mathrm{E}+03$

$\square 1.276 \mathrm{E}+03$

$\square 1.148 \mathrm{E}+03$

$\square 1.021 \mathrm{E}+03$

$\square 8.930 \mathrm{E}+02$

b1)

U, U3

ㅁ $1.348 \mathrm{E}+03$

$\square 1.236 \mathrm{E}+03$

$\square 1.123 \mathrm{E}+03$

$\square 1.011 \mathrm{E}+03$

$\square 8.980 \mathrm{E}+02$

$\square 7.860 \mathrm{E}+02$

c1)
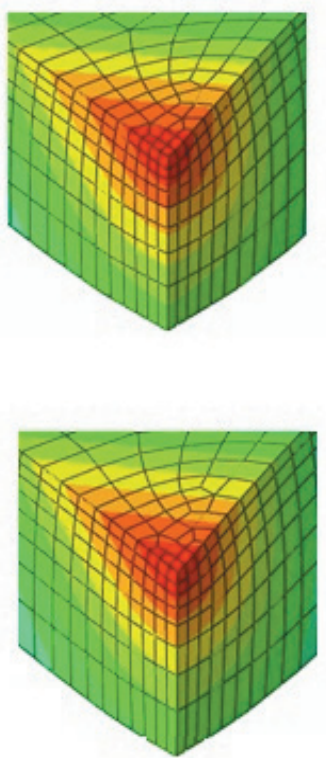

U, U3

$\square 1.252 \mathrm{E}+03$

$\square 1.162 \mathrm{E}+03$

$\square 1.073 \mathrm{E}+03$

$\square 9.830 \mathrm{E}+02$

$\square 8.930 \mathrm{E}+02$

$\square 8.041 \mathrm{E}+03$

d1)

U, U3

$\square 1.206 \mathrm{E}+03$

$\square 1.119 \mathrm{E}+03$

$\square 1.033 \mathrm{E}+03$

$\square 9.450 \mathrm{E}+02$

$\square 8.590 \mathrm{E}+02$

$\square 7.720 \mathrm{E}+02$
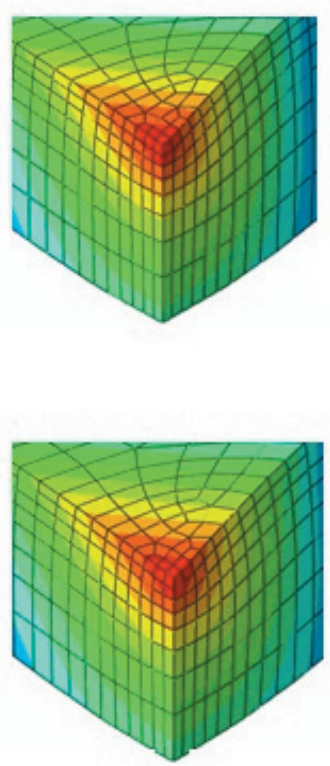

e1)

U, U3

$\square$ 1.191E+03

$\square 1.092 \mathrm{E}+03$

$\square 9.920 \mathrm{E}+02$

$\square 8.930 \mathrm{E}+02$

$\square 7.940 \mathrm{E}+02$

ㄷ. $940 \mathrm{E}+02$ b2)

c2)

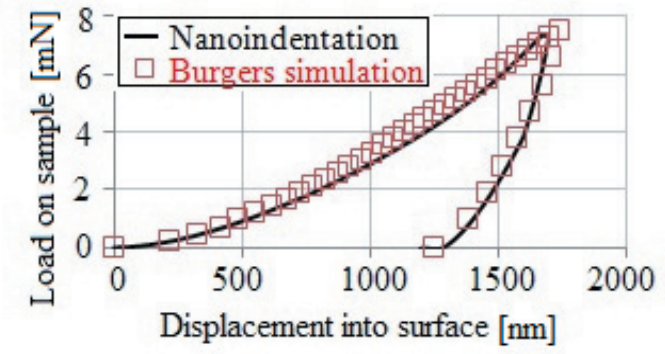

d2)

a2)
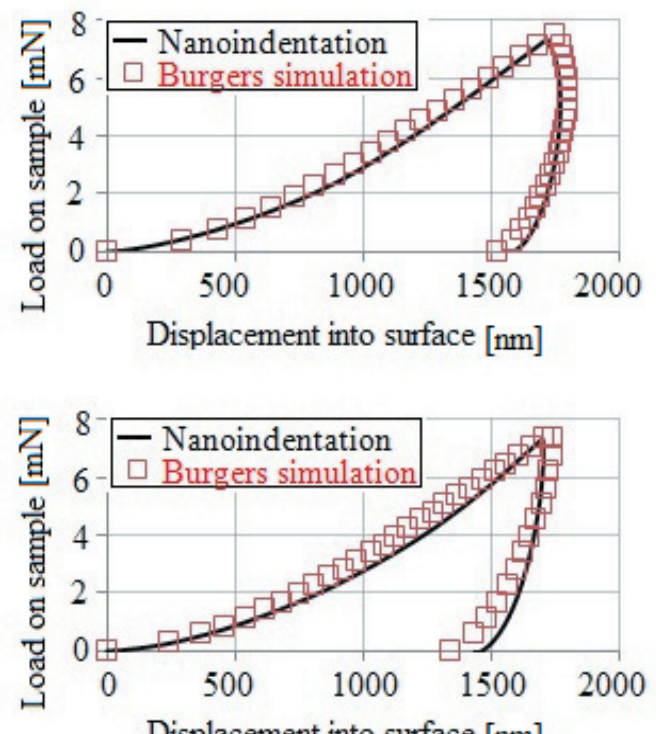

Displacement into surface [nm]

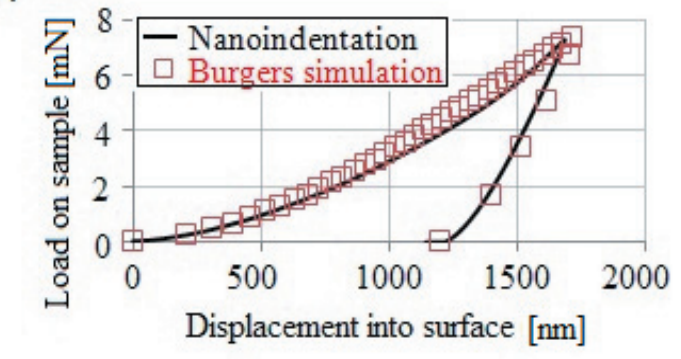

e2)

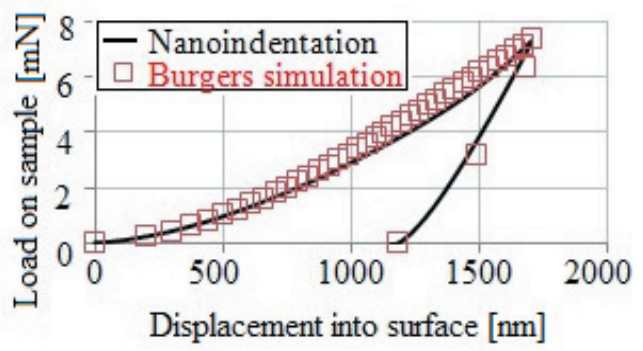

Fig. 2. Comparison of load vs. displacement curves obtained from simulation and nanoindentation results for constant load of $8 \mathrm{mN}$ at different unloading rates of a2) $0.05 \mathrm{mN} / \mathrm{s}$ b2) $0.1 \mathrm{mN} / \mathrm{s}, \mathrm{c} 2) 0.2 \mathrm{mN} / \mathrm{s}, \mathrm{d}$ 2) $0.4 \mathrm{mN} / \mathrm{s}$, e2) $0.8 \mathrm{mN} / \mathrm{s}$ : left column contour plot of the displacements into the surface, right column comparison between the nanoindation experimental data and simulation results 
Table 1. Nonlinear Burgers model parameters used in simulations

\begin{tabular}{|c|c|c|c|c|c|c|c|c|c|c|c|c|}
\hline \multicolumn{2}{|c|}{$\begin{array}{c}\text { Elastic } \\
\text { Parameters }\end{array}$} & & \multicolumn{8}{|c|}{$\begin{array}{l}\text { Transient Parameters } \\
\text { (Voigt Units) }\end{array}$} & \multicolumn{2}{|c|}{$\begin{array}{c}\text { Steady } \\
\text { Parameters }\end{array}$} \\
\hline$E[\mathrm{GPa}]$ & $v$ & & 1 & 2 & 3 & 4 & 5 & 6 & 7 & 8 & $c_{S}$ & $m_{S}$ \\
\hline \multirow[t]{3}{*}{3.5} & 0.35 & $c_{t}$ & 0.85 & 0.70 & 0.70 & 0.70 & 0.70 & 0.4 & 0.05 & 0.05 & 0.040 & 0.060 \\
\hline & & $m_{t}$ & 0.1 & 0.25 & 0.15 & 0.25 & 0.3 & 0.3 & 0.3 & 0.3 & & \\
\hline & & $t_{\xi}[\mathrm{s}]$ & 0.5 & 3 & 50 & 100 & 125 & 150 & 250 & 300 & & \\
\hline
\end{tabular}

rate has strictly effect on the linear and/or nonlinear viscoelastic behaviors of PVAc specimen used.

\section{CONCLUSIONS}

In this study, nonlinear viscoelastic behavior of PVAc has been modeled using a nonlinear Burgers model. A set of parameters in the nonlinear Burgers model were fitted to the nanoindentation load-displacement curve with a peak load of $8 \mathrm{mN}$ under $0.05 \mathrm{mN} / \mathrm{s}$ loading/ unloading rate, and all subsequent simulations were carried out using these parameters. PVAc exhibits a negative stiffness during unloading with slow rates $(0.05$ and $0.1 \mathrm{mN} / \mathrm{s})$. However, if the unloading rate is higher than $0.1 \mathrm{mN} / \mathrm{s}$, PVAc exhibits more elastic behavior. A good agreement can be achieved between simulations and nanoindentation experiments under different unloading rates. The results indicate that the nonlinear Burgers model is capable of modeling the nonlinear behavior of PVAc under different unloading rates from 0.05 to $0.8 \mathrm{mN} / \mathrm{s}$. The unloading rate has explicit effect on the viscos properties of PVAc specimen used. Also, an increase in unloading rate leads to an increase in capability of recovery for PVAc sample. By the use of the model parameters extracted, the further predictions regarding PVAc could be achieved by applying different loading \& unloading conditions.

\section{ACKNOWLEDGEMENT}

The author would like to thank Dr. Hongbing Lu at the University of Texas at Dallas for providing equipment used in this paper, and the support of DOE Nuclear Energy University Program (NEUP) grant 09-416, the ONR MURI BAA 10-026, and NSF CMMI-1031829 \& CMMI-1132174.

\section{REFERENCES}

[1] Oliver, W.C., Pharr, G.M. (1992). An Improved technique for determining hardness and elastic modulus using load and displacement sensing indentation experiments. Journal of Materials Research, vol. 7, no. 6, p. 1564-1583, DOI:10.1557/JMR.1992.1564.

[2] Knauss, W.G., Kenner, V.H. (1980). On the hygrothermomechanical characterization of polyvinyl acetate. Journal of Applied Physics, vol. 51, no. 10, p. 5131-5136, DOI:10.1063/1.327458.

[3] Deng, T.H., Knauss, W.G. (1997). The temperature and frequency dependence of the bulk compliance of poly(vinyl acetate). Mechanics of TimeDependent Materials, vol. 1, no. 1, p. 33-49, DOI:10.1023/A:1009734225304.

[4] Arenz, R.J. (1999). Nonlinear shear behavior of poly(vinyl acetate) material. Mechanics of TimeDependent Materials, vol. 2, no. 4, p. 287-305, DOI:10.1023/A:1009827310712.

[5] Huang, G., Lu, H. (2007). Measurements of two independent viscoelastic functions by nanoindentation. Experimental Mechanics, vol. 47, no. 1, p. 87-98, DOI:10.1007/s11340-006-8277-4.

[6] Lee, E.H., Radok, J.R.M. (1960). The contact problem for viscoelastic bodies. Journal of Applied Mechanics, vol. 27, no. 3, p. 438-444, DOI:10.1115/1.3644020.

[7] Sneddon, I.N. (1965). The relation between load and penetration in the axisymmetric boussinesq problem for a punch of arbitrary profile. International Journal of Engineering Science, vol. 3, no. 1, p. 47-57, DOI:10.1016/0020-7225(65)90019-4.

[8] Hertz, H. (1882). Uber die beruhrung fester elastischer korper. Journal fur die Reine und Angewandte Mathematik, vol. 1882, no. 92, p. 156-171, DOI:10.1515/crll.1882.92.156. (in German)

[9] Harding, J.W., Sneddon, I.N. (1945). The elastic stresses produced by the indentation of the plane surface of a semi-infinite elastic solid by a rigid punch. Proceedings of the Cambridge Philosophical Society, vol. 41, no. 1, p. 16-26, DOI:10.1017/S0305004100022325.

[10] Sneddon, I.N. (1948). Boussinesq's problem for a rigid cone. Proceedings of the Cambridge Philosophical Society, vol. 44, no. 4, p. 492-507, DOI:10.1017/ S0305004100024518.

[11] Kucuk, Y., Mollamahmutoglu, C., Wang, Y., Lu, H. (2013). Nonlinearly viscoelastic nanoindentation of PMMA under a spherical tip. Experimental Mechanics, vol. 53 , no. 5, p. 731-742, DOI:10.1007/s11340-0129695-0.

[12] Shay, R.M., Caruthers, J.M. (1986). A new nonlinear viscoelastic constitutive equation for predicting yield 
in amorphous solid polymers. Journal of Rheology, vol. 30, no. 4, p. 781-827, DOI:10.1122/1.549869.

[13] Knauss, W.G., Emri, I. (1981). Non-linear viscoelasticity based on free volume consideration. Computers and Structures, vol. 13, no. 1-3, p. 123-128, DOI:10.1016/0045-7949(81)90116-4.

[14] Knauss, W.G., Emri, I. (1987). Volume change and the nonlinearly thermo-viscoelastic constitution of polymers. Polymer Engineering and Science, vol. 27, no. 1, p. 86-100, DOI:10.1002/pen.760270113.

[15] Wineman, A.S., Waldron, W.K. (1993). Interaction of nonhomogeneous shear, nonlinear viscoelasticity, and yield of a solid polymer. Polymer Engineering and Science, vol. 33, no. 18, p. 1217-1228, DOI:10.1002/ pen.760331810.

[16] Wang, F. Wang, Y., Fu, B., Lu, H. (2011). Nonlinear viscoelastic nanoindentation of PVAc. Conference
Proceedings of the SEM Series, vol. 15, p. 93-100, DOI:10.1007/978-1-4419-9794-4 16.

[17] Chen, D-L., Yang, P-F., Lai Y-S. (2012). A review of three-dimensional viscoelastic models with an application to viscoelasticity characterization using nanoindentation Microelectronics Reliability, vol. 52, no. 3, p. 541-558, DOI:10.1016/j.microrel.2011.10.001.

[18] Ferry, J.D. (1980). Viscoelastic properties of polymers, $3^{\text {rd }}$ ed. John Wiley\&Sons, New York.

[19] Findley, W.N., Lai, J.S., Onaran, K. (1989). Creep and Relaxation of Nonlinear Viscoelastic Materials with an Introduction to Linear Viscoelasticity, 1 ${ }^{\text {st }}$ ed., Dover Pub., New York.

[20] Richter, H., Misawa, E.A., Lucca, D.A., Lu, H. (2001). Modeling nonlinear behavior in a piezoelectric actuator. Precision Engineering, vol. 25, no. 2, p. 128137, DOI:10.1016/S0141-6359(00)00067-2. 